\title{
Design of Fe-Mn-Ag Alloys as Potential Candidates for Biodegradable Metals
}

\author{
Ruo-Yu Liu' ${ }^{1}$ Ran-Gan $\mathrm{He}^{1} \cdot \mathrm{Li}^{-Q u n} \mathrm{Xu}^{1} \cdot$ Sheng-Feng Guo ${ }^{1}$
}

Received: 16 October 2017 / Revised: 21 December 2017/Published online: 29 January 2018

(C) The Chinese Society for Metals and Springer-Verlag GmbH Germany, part of Springer Nature 2018

\begin{abstract}
In this work, a series of biodegradable pure iron, $\mathrm{Fe}-30 \mathrm{Mn}$ and $\mathrm{Fe}-30 \mathrm{Mn}-\mathrm{Ag}$ alloys were developed by using a rapid solidification technology. A fine $\alpha$-Fe dendrite was formed in pure iron, resulting in a high compressive yield strength of above $300 \mathrm{MPa}$. The Fe-30Mn alloy doped with only $1 \% \mathrm{Ag}$ exhibited a significant increase in the degradation rate in simulated body fluid due to the precipitation of $\mathrm{Ag}$-rich particles in alloy matrix and the induction of the microgalvanic corrosion. In addition, the novel $\mathrm{Fe}-30 \mathrm{Mn}-\mathrm{Ag}$ alloy also exhibited a good magnetic compatibility and offered a closely approaching requirement for biodegradable medical applications.
\end{abstract}

Keywords Biodegradable metals $\cdot$ Fe-based alloys $\cdot$ Corrosion rate $\cdot$ Magnetic compatibility

\section{Introduction}

Compared with plastics and ceramics, the metals represented by stainless steels, Ti-based alloys and Co-based alloys have the longest history for the use in biomedical applications and still play an important role. The traditional paradigm of these alloys demanded the metallic biomaterials with excellent corrosion resistance in the human body [1]. Unfortunately, some complications were the common consequences of the use of these metals as long-term implants. These problems maybe result from the release of toxic ions, such as $\mathrm{Ni}, \mathrm{V}$ and $\mathrm{Cr}$, which were common elements fabricated in many biomedical metals [2]. In fact, in certain cases, it has been realized that the permanent bioinert was no longer necessary and would be replaced by the degradable implants especially used for orthopedic and cardiovascular applications [3].

Biodegradable metals were a new generation of biomedical materials, which began to develop rapidly at the beginning of this century. These novel biodegradable metals have abandoned the traditional idea that the metallic

Available online at http://link.springer.com/journal/40195

\section{Sheng-Feng Guo}

sfguo@swu.edu.cn

1 Faculty of Materials and Energy, Southwest University, Chongqing 400715, China implants are commonly used as bioinert, which in turn expected to corrode in vivo with an appropriate repair function and degrade gradually until the final disappearance for the clinical purpose [4-6]. Therefore, the chemical composition of biodegradable metals should be essential metallic elements that can be metabolized by the human body. In this context, biodegradable $\mathrm{Mg}$ and $\mathrm{Fe}$ alloys were very promising candidates for such applications. Although $\mathrm{Mg}$ alloys exhibited an excellent biodegradability and biocompatibility, the too fast degradation rates in human body would disable the host response of these materials [7-10]. In another case, pure iron as a degradable implant has been examined in preliminary in vitro [11] and animal model investigations $[12,13]$, demonstrating that pure iron was a suitable metal for the degradable stent without local or systemic toxicity. However, pure iron remained relatively intact when its service is up to one year, implying that the degradation rate of the pure iron was too slow. More seriously, the magnetic compatibility of pure iron was not well suitable for implant materials. Therefore, development of novel Fe-based alloys to expedite the degradation process with good magnetic compatibility was highly desirable.

Recently, a series of biodegradable Fe-Mn alloys were proposed owing to their accelerated corrosion behavior, enhanced mechanical properties and compatibility with the magnetic resonance imaging with respect to pure iron $[14,15]$. However, the degradation rate of these alloys was 
still too low for many temporary implant applications. Furthermore, microalloying with C [16], Si [17] or Pd [18] in Fe-Mn biodegradable alloys has been demonstrated as one of the effective ways to accelerate the degradation rate and improve the biocompatibility. To further explore the possibilities of biodegradable Fe-based alloys, design of $\mathrm{Fe}-\mathrm{Mn}-\mathrm{Ag}$ alloys was presented in this work based on the following considerations. (1) Fe and Mn could form a solid solution with an austenite structure, which lower the standard electrode potential and magnetic susceptibility of iron; and (2) based on the theory of solid solution in $\mathrm{Fe}-$ $\mathrm{Mn}-\mathrm{Ag}$ alloy, the formation of noble Ag-rich precipitates in the matrix was expected to induce microgalvanic corrosion, which may greatly enhance the degradation rate [19]; and (3) from a biological point of view, silver ions have shown to possess strong antimicrobial properties but cause no immediate and serious risk for human health, which led to an extensive use of silver-bearing materials in many biomedical applications [20]. Therefore, microalloying with Ag for a new biodegradable Fe-based alloy was developed and assessed for their degradation characteristics, mechanical performance, antimicrobial properties and magnetic susceptibility, respectively.

\section{Experimental}

Each master alloy with total weight of about $10 \mathrm{~g}$ pure Fe, $\mathrm{Fe}-30 \mathrm{Mn}$ and $\mathrm{Fe}-30 \mathrm{Mn}-\mathrm{Ag}$ metals was prepared by arc melting under high vacuum with an Ar atmosphere using industrial purity $\mathrm{Fe}(99.5 \%), \mathrm{Mn}(99.9 \%)$ and $\mathrm{Ag}$ sheet $(99.99 \%)$. The cylindrical rods with $3 \mathrm{~mm}$ in diameter and $50 \mathrm{~mm}$ in length were fabricated by the rapid solidification using copper mold suction casting. The quantitative chemical analysis of the fabricated $\mathrm{Fe}-30 \mathrm{Mn}$ and $\mathrm{Fe}-$ 30Mn-Ag alloys was determined by X-ray fluorescence analyzer (Shimadzu, XRF-1800). The final concentration of the elements of the two alloys was Fe70.8-Mn29.2 and Fe70.3-28.9Mn-0.8Ag, respectively. The microstructure and phase composition of the as-cast alloys were examined by X-ray diffraction (XRD, Rigaku D/MAX-2500/PC) using a $\mathrm{Cu} K_{\alpha}$ source operated at $35 \mathrm{kV}$ and $30 \mathrm{~mA}$, and scanning electron microscopy (SEM, JSM-6610) equipped with an X-ray energy-dispersive spectrometer (EDS), respectively. The uniaxial compression of specimens with an aspect ratio of 2:1 was cut using a low-speed diamond saw and carried out on a mechanical testing machine (Reger, RGM-4100) at a strain rate of $5 \times 10^{-4} \mathrm{~s}^{-1}$. Magnetic susceptibility was measured by a vibrating sample magnetometer (Quantum Design, VersaLab) using a weight of $10-15 \mathrm{mg}$ powders.

Prior to the electrochemical measurements, all the samples were embedded in epoxy resin leaving only an end surface area exposed to the solution. The exposed surface was wet-ground to 3000 grit using SiC paper, followed by ultrasonic cleaning in ethanol, and then washed in distilled water and dried in warm air. Electrochemical polarization tests were performed in a simulated body fluid (Hank's, composition given in Table 1 ) at $37 \pm 0.5^{\circ} \mathrm{C}$ conducted in a three-electrode cell using a platinum counter electrode and a saturated calomel reference electrode (SCE) under an electrochemical workstation (CHI660E). First, before the open-circuit potential test, the specimens were immersed for $20 \mathrm{~min}$ to ensure the stability of the follow-up experiment. When the open-circuit potential reached a steady state, the potentiodynamic polarization curves of the specimens were recorded at a potential sweep rate of $0.33 \mathrm{mV} / \mathrm{s}$. At least three tests were repeated for each alloy to ensure data reproduction and their average values were reported. The electrochemical impedance spectroscopy (EIS) was examined at the open-circuit potential with sinusoidal amplitude of $10 \mathrm{mV}$ in the frequency ranging from $100 \mathrm{kHz}$ to $10 \mathrm{MHz}$. SEM with EDS was also used to characterize the corrosion morphologies and the chemical composition of products. The static immersion tests were performed following ASTM-G31-72 at $37{ }^{\circ} \mathrm{C}$ in water bath for 7 and 14 days, respectively. The concentrations of various elements released into the solutions after immersed for 14 days were determined by ICP-OES (PerkinElmer, Optima 8000).

E. coli and $S$. aureus were cultured according to the ATCC protocols/specifications. The bacterial suspensions were then dispersed in phosphate-buffered saline (PBS) solution, with $\mathrm{pH} 7.4$, to give rise to a final concentration of $1 \times 10^{5}$ bacterial cells per mL. Then, $500 \mu \mathrm{L}$ bacterial suspension was mixed with the samples or PBS. After 4-h culturing at $37^{\circ} \mathrm{C}, 100 \mu \mathrm{L}$ solution was introduced into tryptic soy broth (TSB). After that, the mixture was added into each well of a 96-well plate. And the plate was incubated at $37{ }^{\circ} \mathrm{C}$. In addition, the time-dependent optical density (OD) of each well at $630 \mathrm{~nm}$ was recorded on a microplate reader (BioTek Instruments ELX800, USA). Controlled experiment was carried out by using PBS solution to culture with the bacteria [21].

\section{Results and Discussion}

Figure 1 shows the XRD patterns of the three different ascast samples. According to the standard PDF card (Reference code: 06-0696), it can be identified to the formation of single ferrite $\alpha$-Fe phase with a bcc structure for the pure iron even using the rapid solidification technology. However, with a mass ratio of $30 \% \mathrm{Mn}$ addition, the phase composition and crystal structure of Fe-30Mn alloy consisted of austenite $\gamma$ phase with a fcc structure and 
Table 1 Chemical composition of Hank's solution

\begin{tabular}{llllllll}
\hline Composition & $\mathrm{NaCl}$ & $\mathrm{KCl}$ & $\mathrm{CaCl}_{2}$ & $\mathrm{NaHCO}_{3}$ & $\mathrm{MgSO}_{4}$ & $\mathrm{Na}_{2} \mathrm{HPO}_{4}$ & $\mathrm{KH}_{2} \mathrm{PO}_{4}$ \\
\hline Mass $(\mathrm{g} / \mathrm{L})$ & 8 & 0.4 & 0.14 & 0.35 & 0.059 & 0.024 & 0.06 \\
\hline
\end{tabular}

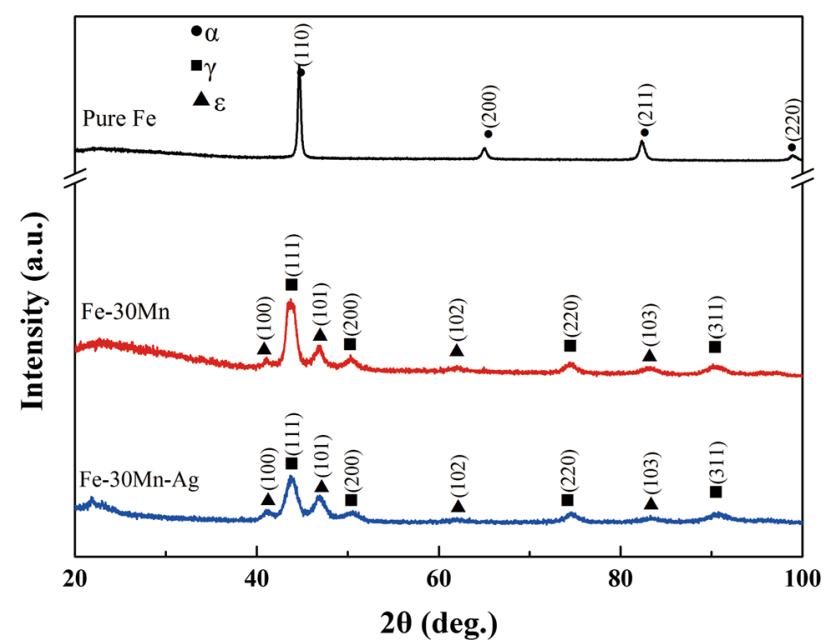

Fig. 1 XRD patterns of as-cast pure Fe and Fe-based alloys obtained by rapid solidification

martensite $\varepsilon$ phase with a hcp structure. Furthermore, after a little silver addition, the phase composition and crystal structure of $\mathrm{Fe}-30 \mathrm{Mn}-\mathrm{Ag}$ alloy were very similar to Fe30Mn alloy. Followed by the Rietveld refinement of $\mathrm{XRD}$, it demonstrated that the content of the austenite $\gamma$ phase was reduced slightly and the lattice constants of the Ag-bearing alloy were increased.

Figure 2 shows the SEM images of microstructural morphologies for the three different Fe-based alloys. It exhibited an ultra-fine dendrite of the pure iron due to the rapid solidification process (see Fig. 2a). For Fe-30Mn alloy, the coarsening dendrites obviously appeared (see Fig. 2b). Interestingly, for the Ag-bearing Fe-based alloy, some bright particles were precipitated on the grain boundaries (see Fig. 2c). In order to explore the composition of these particles, the EDS point analysis was performed, revealing that these small particles were Ag-rich $\gamma-\mathrm{Fe} 70 \mathrm{Mn} 30$ phases.
Engineering stress-strain curves obtained by the compressive tests of the specimens are shown in Fig. 3. It was worth mentioning that the compressive yield strength of pure iron in present work could reach $320 \mathrm{MPa}$, which was more than four times higher than that of the alloy obtained by traditional casting method (73 MPa) [22]. This probably originated from the strongly fine-grained strengthening by rapid solidification processing. The cooling rate of the current pure iron was at least two orders of magnitude higher than that of the conventional casting [23]. The rapid quenching of pure iron resulted in a high yield strength, which was approaching to the electroformed iron foils (360 MPa) [24], being superior to those of other metallic biodegradable stent materials. However, the yield strength of as-cast Fe-30Mn alloy was only about $94 \mathrm{MPa}$ due to the formation of the $\gamma$ phase with a fcc structure. Interestingly, for the $\mathrm{Fe}-30 \mathrm{Mn}-\mathrm{Ag}$ alloy, the compressive yield strength was significantly increased to $130 \mathrm{MPa}$ due to the combination of their fine microstructure and the precipitation of Ag-rich particles on the grain boundaries, which was induced by the precipitation strengthening and resulted in a significantly increased yield strength. In addition, all of the Fe-based alloys exhibited an excellent room-temperature deformation ability, implying that they were very favorable for the subsequent processing and shaping the implants. The detailed characterization of the mechanical properties is shown in Table 2.

The open-circuit potential (OCP) was the potential of working electrode relative to the reference electrode at which there was no any applied current, reflecting the thermodynamic equilibrium at the interface between the alloy and solution as a function of time. Figure 4 a displays the OCP variation of three different alloys during the immersion time up to $3600 \mathrm{~s}$. It can be seen that the OCPs with little fluctuations start maintaining relatively stable values after immersing for about $10 \mathrm{~min}$, indicating
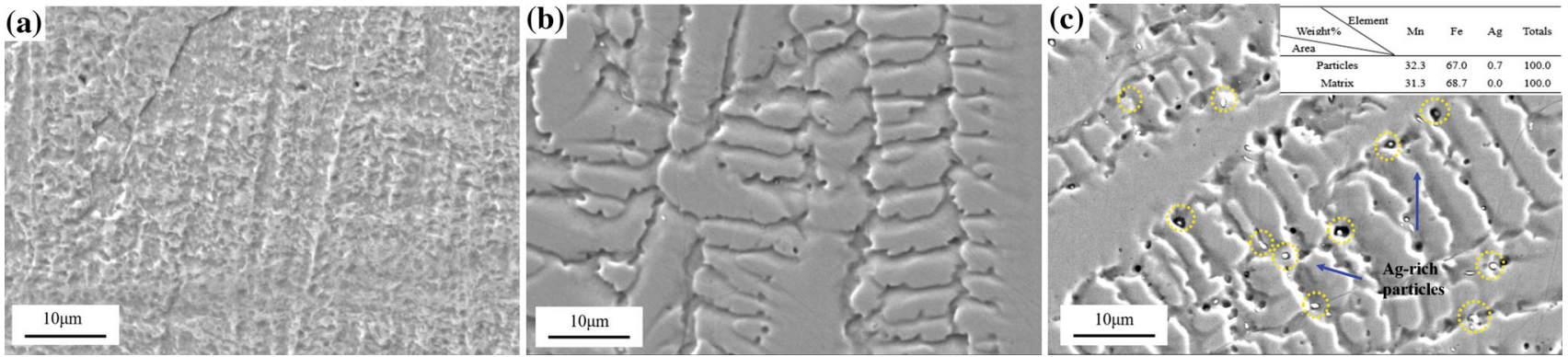

Fig. 2 SEM backscattered electron images of pure $\mathrm{Fe}(\mathbf{a})$; $\mathrm{Fe}-30 \mathrm{Mn}(\mathbf{b}) ; \mathrm{Fe}-30 \mathrm{Mn}-\mathrm{Ag}$ (c) alloys, respectively 
the formation of stable passive films on the samples [25]. The OCP value of pure iron was about $-0.62 \mathrm{~V}$ as summarized in Table 2. Importantly, compared with pure iron, the OCP values of the $\mathrm{Fe}-30 \mathrm{Mn}$ and Ag-bearing alloy depicted a remarkable decrease to $-0.80 \mathrm{~V}$ (SCE) and $-0.79 \mathrm{~V}$ (SCE), respectively. This could be attributed to the fact that $\mathrm{Fe}$ and $\mathrm{Mn}$ form a solid solution with an austenite structure and lower the standard electrode potential. The large decreased OCP suggested that the $\mathrm{Fe}-$ $30 \mathrm{Mn}$ and $\mathrm{Fe}-30 \mathrm{Mn}-\mathrm{Ag}$ alloys made the spontaneous passive film more unstable thermodynamically.

Figure $4 \mathrm{~b}$ shows the potentiodynamic polarization curves of the three samples immersed in Hank's solution.

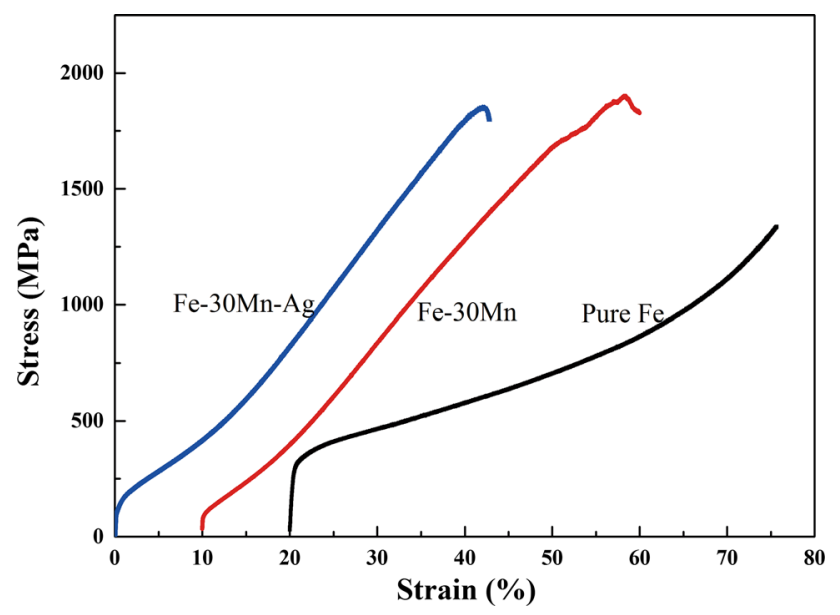

The corrosion-related kinetic parameters including the corrosion potential $\left(E_{\text {corr }}\right)$ and the corrosion current density $\left(i_{\text {corr }}\right)$ are identified by Tafel extrapolation method and also summarized in Table 2. Compared with pure iron, the $E_{\text {corr }}$ of $\mathrm{Fe}-30 \mathrm{Mn}$ alloy was decreased largely and the $i_{\text {corr }}$ was increased [17]. Furthermore, for the Ag-bearing alloy, the potentiodynamic polarization curve was moved to the top left as a whole, implying that the corrosion rate was further increased. The standard electrode potentials of iron, manganese and silver were $-0.44,-2.37$ and $0.799 \mathrm{~V}$, respectively. Due to the different potential differences, the galvanic corrosion could be introduced into the $\mathrm{Fe}-30 \mathrm{Mn}$ and Ag-bearing alloy in Hank's solution. Moreover, the potential difference between silver and manganese $(3.169 \mathrm{~V})$ was higher than that of iron-manganese $(1.93 \mathrm{~V})$. Therefore, the addition of silver to ferromanganese alloy had a greater degree of corrosion than that of $\mathrm{Fe}-30 \mathrm{Mn}$ alloy. In addition, it was recognized that $\alpha$-ferrite was more resistant to corrosion than $\varepsilon$-martensite and $\gamma$ austenite [26]. Indeed, the $i_{\text {corr }}$ of Fe-30Mn-Ag alloy was much higher than that of pure Fe. From the microgalvanic corrosion, the specific surface area and the surface energy of Ag-rich particles were significantly higher than that of the rest of $\mathrm{Fe}-\mathrm{Mn}$ matrix. Therefore, the $\mathrm{Fe}-\mathrm{Mn}$ matrix would be oxidized, acting as the anode as shown in Eqs. (1) and (2). The electrons generated from the dissolving $\mathrm{Fe}-\mathrm{Mn}$ matrix would transfer to the Ag-rich particles served as the cathode and, then, would be consumed by dissolved oxygen, as shown in Eq. (3).

Fig. 3 Compressive strain-stress curves of different alloys

Table 2 Electrochemical, mechanical properties and magnetic susceptibility of the samples

\begin{tabular}{lllllllll}
\hline Samples & OCP $(\mathrm{V})$ & $E_{\text {corr }}(\mathrm{V})$ & $i_{\text {corr }}\left(\mu \mathrm{A} / \mathrm{cm}^{2}\right)$ & $R_{\mathrm{p}}\left(\Omega / \mathrm{cm}^{2}\right)$ & $P(\mathrm{~mm} /$ year $)$ & YS $(\mathrm{MPa})$ & Plastic strain $(\%)$ & $\chi\left(\mathrm{m}^{3} / \mathrm{kg}\right)$ \\
\hline $\mathrm{Fe}$ & -0.62 & -0.97 & $0.58 \pm 0.04$ & $5.09 \times 10^{6}$ & 0.007 & $320 \pm 23$ & $>50$ & $3.7 \times 10^{-4}$ \\
$\mathrm{Fe}-30 \mathrm{Mn}$ & -0.80 & -1.11 & $0.60 \pm 0.06$ & $4.07 \times 10^{6}$ & 0.007 & $94 \pm 11$ & $42 \pm 3$ & $2.76 \times 10^{-6}$ \\
$\mathrm{Fe}-30 \mathrm{Mn}-\mathrm{Ag}$ & -0.79 & -1.10 & $0.89 \pm 0.14$ & $2.86 \times 10^{6}$ & 0.012 & $130 \pm 10$ & $38 \pm 4$ & $2.16 \times 10^{-6}$ \\
\hline
\end{tabular}
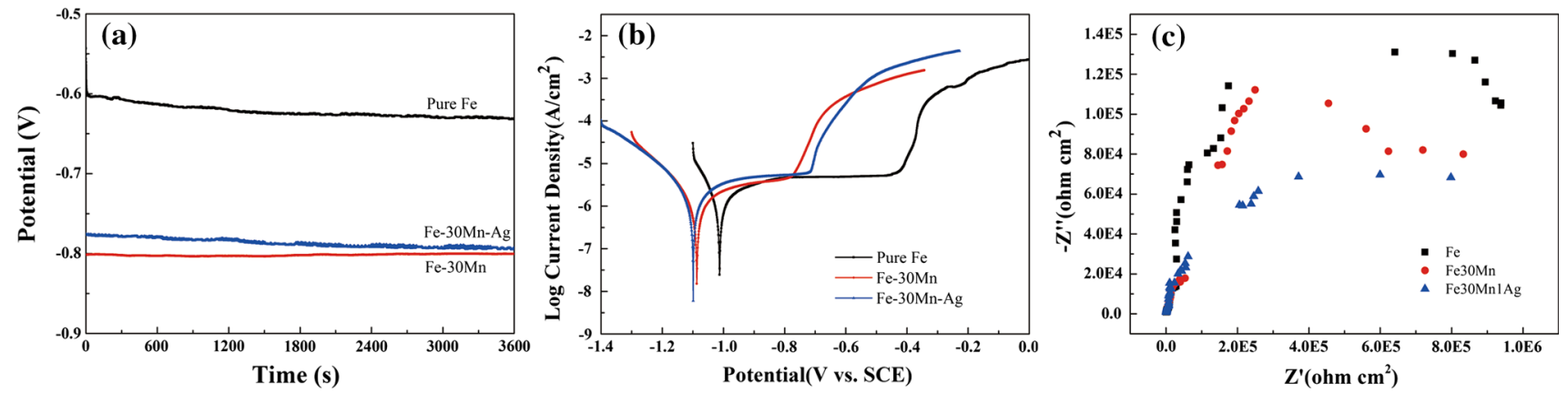

Fig. 4 OCP (a); potentiodynamic polarization curves (b); the Nyquist plots (c) of different samples in Hank's solution 
$\mathrm{Fe} \rightarrow \mathrm{Fe}^{2+}+2 \mathrm{e}^{-}$(anode reaction)

$\mathrm{Mn} \rightarrow \mathrm{Mn}^{2+}+2 \mathrm{e}^{-}$(anode reaction).

$2 \mathrm{H}_{2} \mathrm{O}+\mathrm{O}_{2}+4 \mathrm{e}^{-} \rightarrow 4 \mathrm{OH}^{-}$(cathode reaction)

Due to the solution alkalization near the Ag-enriched particles [Eq. (3)], iron hydroxide would be formed according to Eq. (4). Because the ferrous hydroxide was thermodynamically unstable, it would be oxidized to ferric hydroxide, the reaction as shown in Eq. (5):

$\mathrm{Fe}^{2+}+2 \mathrm{OH}^{-} \rightarrow \mathrm{Fe}(\mathrm{OH})_{2}$.

$4 \mathrm{Fe}(\mathrm{OH})_{2}+\mathrm{O}_{2}+2 \mathrm{H}_{2} \mathrm{O} \rightarrow 4 \mathrm{Fe}(\mathrm{OH})_{3}$.

With the increase in corrosion depth, the galvanic corrosion process was repeated. Based on the electrochemical results, it can be found that the order of $i_{\text {corr }}$ follows: $\mathrm{Fe}-$ $30 \mathrm{Mn}-\mathrm{Ag}>\mathrm{Fe}-30 \mathrm{Mn}>\mathrm{Fe}$. The Fe-30Mn-Ag alloy exhibited a lower value of $E_{\text {corr }}$ and a higher value of $i_{\text {corr }}$ than $\mathrm{Fe}-30 \mathrm{Mn}$ and pure $\mathrm{Fe}$, indicating that the Ag-bearing alloy significantly increases the degradation rate.

Figure $4 \mathrm{c}$ shows the electrochemical impedance spectroscopy (EIS) of different samples in Hank's solution. It can be clearly seen that the order of the electrochemical impedance of the three samples was $\mathrm{Fe}>\mathrm{Fe}-30 \mathrm{Mn}>\mathrm{Fe}-$ $30 \mathrm{Mn}-\mathrm{Ag}$, which was consistent well with the order of magnitude of the polarization resistance $\left(R_{\mathrm{p}}\right)$, calculated by means of the Stern-Geary equation:

$i_{\text {corr }}=\frac{\left(\beta_{\mathrm{a}} \times \beta_{\mathrm{c}}\right)}{\left(2.3 R_{\mathrm{p}} \times\left(\beta_{\mathrm{a}}+\beta_{\mathrm{c}}\right)\right.}$,

where $\beta_{\mathrm{a}}$ and $\beta_{\mathrm{c}}$ were the slope of the anodic and cathodic Tafel slopes that were obtained by tangent through the Tafel curve [27].

Furthermore, according to Faraday's law [28], the corrosion rate can be calculated using the $i_{\text {corr }}$, as shown in Eq. (7).

$P=0.00327 \frac{\mathrm{EW} \times i_{\mathrm{corr}}}{d}$,

where $P$ is the corrosion rate ( $\mathrm{mm} /$ year), EW is the equivalent weight, $i_{\text {corr }}$ is the corrosion current density $(\mu \mathrm{A} /$ $\left.\mathrm{cm}^{2}\right)$ and $d$ is the density $\left(\mathrm{g} / \mathrm{cm}^{3}\right)$.

The EW of each coupon was calculated according to the following equation [28].

$\mathrm{EW}=\sum \frac{f_{\mathrm{i}} a_{\mathrm{i}}}{n_{\mathrm{i}}}$

where $f_{\mathrm{i}}$ is the mass fraction, $a_{\mathrm{i}}$ is the atomic weight and $n_{\mathrm{i}}$ is the valence electrons of each element in the alloy. The corrosion rate of $\mathrm{Fe}-30 \mathrm{Mn}-\mathrm{Ag}$ alloy could be determined to be $0.01 \mathrm{~mm} / \mathrm{year}$, which was higher than those of $\mathrm{Fe}-$ $30 \mathrm{Mn}$ and pure $\mathrm{Fe}$. Although the in vivo degradation rate was known to be much slower than that of in vitro condition [29], this phenomenon of accelerated corrosion rate was still desirable to what was expected.

To further understand the corrosion behavior of the different Fe-based alloys, SEM was employed to investigate the morphologies of the samples after corrosion. Figure 5 shows the SEM images of samples, which were anodically polarized to the stage where pitting corrosion had just started (i.e., a stage corresponding to a rapid increase in the anodic current density in the polarization curve). It can be seen that the distinct pits appeared on the surface of the pure Fe sample (see Fig. 5a) while the bare dendrites were found on the $\mathrm{Fe}-30 \mathrm{Mn}$ and Ag-bearing alloys by selective dissolving of the main Fe-Mn matrix (see Fig. 5b, c). The depth of dendritic corrosion appeared on the Ag-bearing alloy became much deeper, implying the increase in the degradation rate. After the electrochemical corrosion, there were a large amount of granular particles around the pits. The composition of these corrosion products was measured by EDS mapping scanning in the framed area. It revealed the presence of oxygen, phosphorus and calcium on the surface of the sample after the potentiodynamic polarization. The presence of $\mathrm{Ca}$ and $\mathrm{P}$ could lead to the formation of hydroxyapatite, demonstrating that the present Fe-based alloys were considered biocompatible and especially good candidates for bone implants [22], even though their suitability for the temporary replacement of bones or as osteosynthesis material still appeared questionable.

Furthermore, the static immersion tests were performed on three different specimens. For pure Fe and Fe-30Mn alloys, the weight loss was not obviously changed during the immersion up to 14 days. However, the weight loss of the Ag-bearing Fe-based alloy was about $0.1 \%$ after immersion for 14 days. The degradation rates for $\mathrm{Fe}-$ $30 \mathrm{Mn}-\mathrm{Ag}$ alloy were 0.053 and $0.03 \mathrm{mg} \mathrm{cm}^{-2} \mathrm{day}^{-1}$ for 7 and 14 days, respectively. This calculation was based on the immersion tests using the following formula:

$\mathrm{CR}=\frac{m}{S t}$,

where CR ( $\mathrm{mg} \mathrm{cm}^{-2}$ day $^{-1}$ ) was the corrosion rate, $m(\mathrm{mg})$ was the mass loss, $S\left(\mathrm{~cm}^{2}\right)$ was the surface area of the specimen exposed to the solution and $t$ (day) was the immersion time. Figure 6 reveals the released ion concentrations of Fe and $\mathrm{Mn}$ in Hank's solution for 14 days. It can be found that the order of released ion concentrations of three metals was: $\mathrm{Fe}-30 \mathrm{Mn}-\mathrm{Ag}>\mathrm{Fe}>\mathrm{Fe}-30 \mathrm{Mn}$. Clearly, the corrosion rate of Ag-bearing alloy was faster than the other two metals. It should be mentioned that the mainly released ion was $\mathrm{Mn}$ ion for $\mathrm{Fe}-30 \mathrm{Mn}$ and $\mathrm{Fe}-$ $30 \mathrm{Mn}-\mathrm{Ag}$ alloys. Most of the corrosion products were insoluble Fe-containing products and were not dissolved in the solutions before the ICP-OES test. 

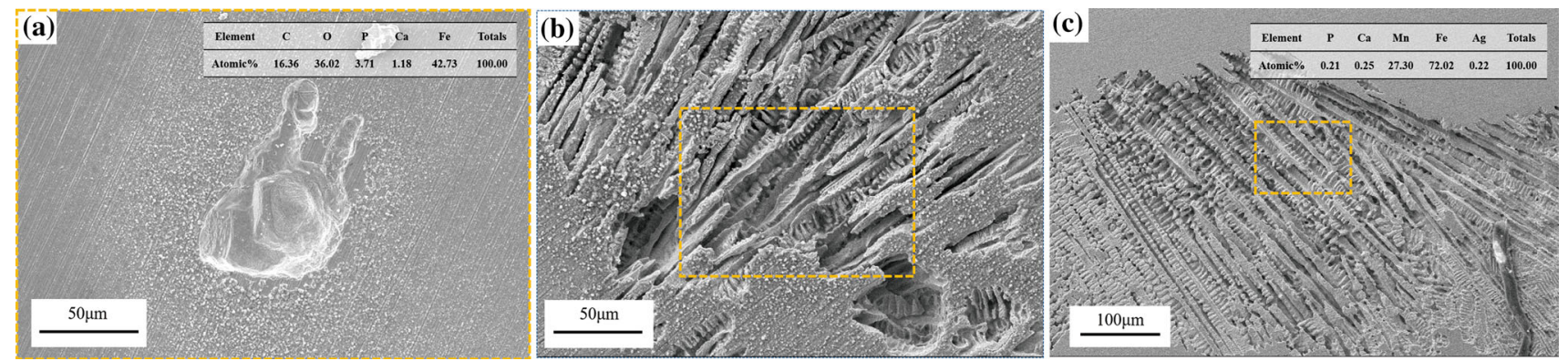

Fig. 5 SEM images of the corrosion morphologies of the samples after pitting and the EDS mapping scanning of the corrosion products (inserts)

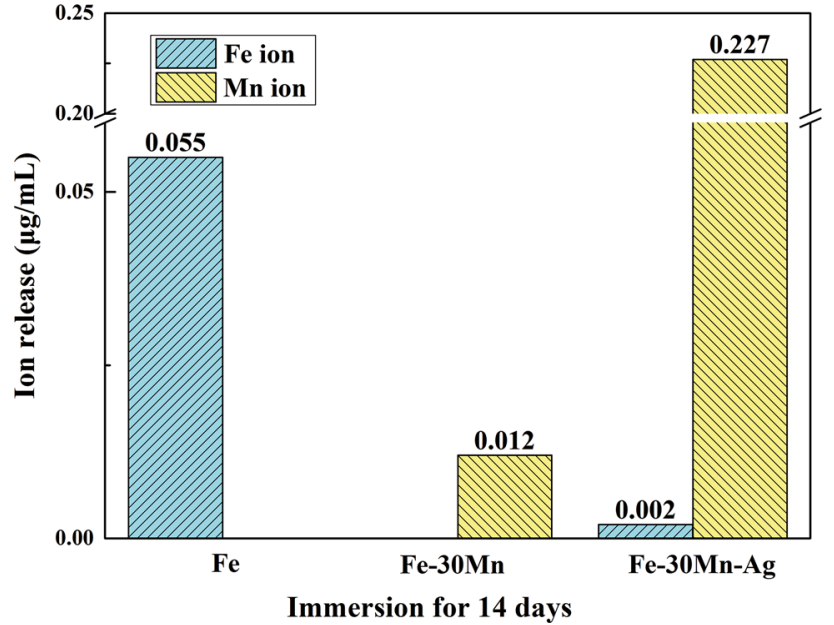

Fig. 6 Released ion concentrations of three different metals in Hank's solution for 14 days

Figure 7 shows the growth curves of the bacteria. It can be seen that the growth trends of E. coli (Fig. 7a) and $S$. aureus (Fig. 7b) were consistent with the control group. Overall, the bacteria were not obviously suppressed after $24 \mathrm{~h}$ for three different metals. This was mainly due to the very slow degradation rate for pure $\mathrm{Fe}$ and $\mathrm{Fe}$-based alloys and almost no released ion concentrations in bacterial

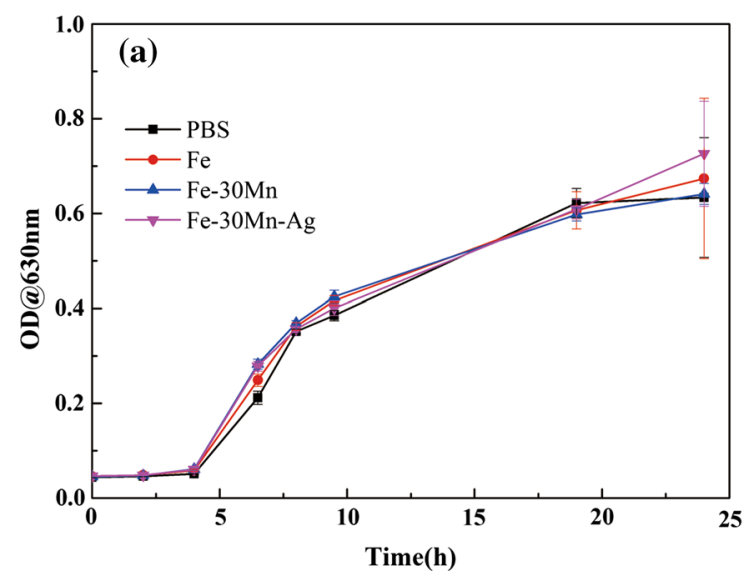

Fig. 7 Growth curves of E. coli (a); S. aureus (b) suspension. In fact, for $\mathrm{Fe}-30 \mathrm{Mn}-\mathrm{Ag}$ alloy, there was no any $\mathrm{Ag}$ ion release in Hank's solution for immersion time of 30 days. There was a very small amount of silver in $\mathrm{Fe}-$ Mn matrix during the present rapid solidification, even though the content of silver was not detected due to the limits of EDS. A trace of silver ions probably was released from the $\mathrm{Fe}-\mathrm{Mn}$ matrix, which acted as the anode. Therefore, it was necessary to further investigate the antibacterial properties of this Ag-bearing Fe-based alloy in a long-term growth of the bacteria, especially after the $\mathrm{Ag}$ ion released.

Figure 8 shows the magnetic-field dependence of the magnetization measured at room temperature for different alloys. All the hysteresis loops show positive $M / H$ slopes, indicating their paramagnetism nature. Compared with pure iron, the $\mathrm{Fe}-30 \mathrm{Mn}$ alloy had a lower $M / H$ slope and smaller area of hysteresis loops. Especially, the magnetic susceptibility $\chi\left(\mathrm{m}^{3} / \mathrm{kg}\right)$ was reduced dramatically by two orders of magnitude from pure $\mathrm{Fe}\left(3.7 \times 10^{-4} \mathrm{~m}^{3} / \mathrm{kg}\right)$ to $\mathrm{Fe}-30 \mathrm{Mn}$ alloy $\left(2.76 \times 10^{-6} \mathrm{~m}^{3} / \mathrm{kg}\right)$. The results confirmed again that the addition of manganese in Fe-based alloys could enhance the compatibility with the magnetic resonance imaging (MRI) due to the formation of austenitic phase. With a mass ratio of only $1 \% \mathrm{Ag}$ doping, the magnetic susceptibility of $\mathrm{Fe}-30 \mathrm{Mn}-\mathrm{Ag}$ alloy was

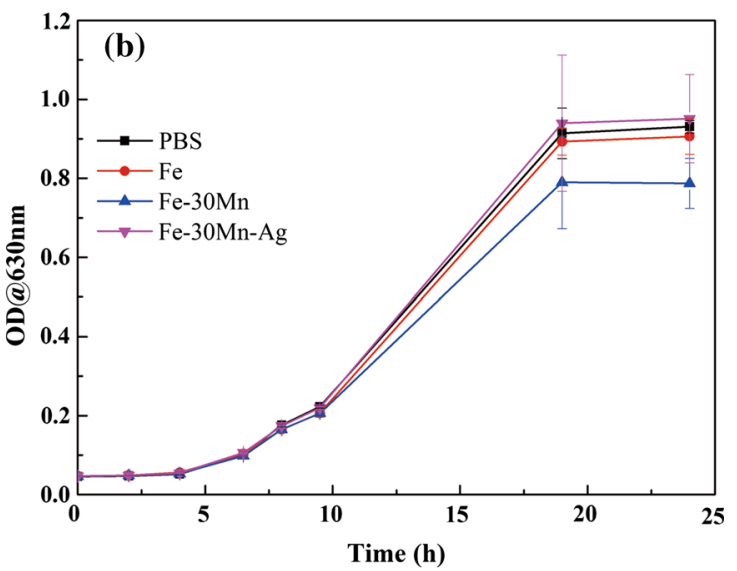




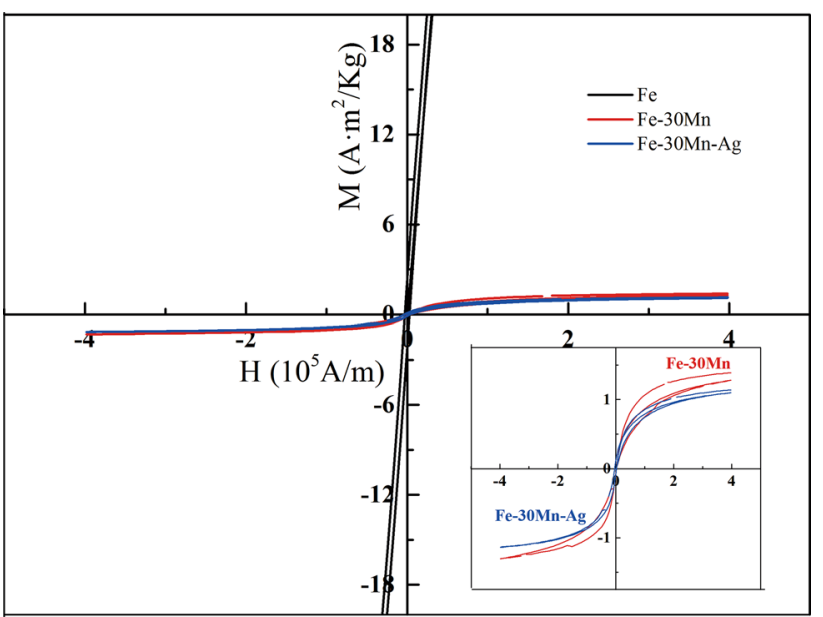

Fig. 8 Magnetic hysteresis loops of the three different metals

decreased gradually to $2.16 \times 10^{-6} \mathrm{~m}^{3} / \mathrm{kg}$ (see Table 2), which was comparable to that of the commonly accepted SS316L stainless steel [15]. The lower magnetic susceptibility of biodegradable Fe-based alloy was favorable for the improvement in nuclear magnetic resonance compatibility.

\section{Conclusion}

In this study, pure $\mathrm{Fe}, \mathrm{Fe}-30 \mathrm{Mn}$ and $\mathrm{Fe}-30 \mathrm{Mn}-\mathrm{Ag}$ alloys were successfully prepared by rapid solidification using copper mold casting with water cooling. The as-cast pure $\mathrm{Fe}$ with fine dendrites shows a high compressive yield strength of above $300 \mathrm{MPa}$ due to its rapid cooling process. The $\mathrm{Fe}-30 \mathrm{Mn}$ alloy exhibited an improved degradation rate in simulated body fluid and a decreased magnetic susceptibility due to the formation of mainly austenitic phase. Furthermore, with only $1 \% \mathrm{Ag}$ doped, the $\mathrm{Fe}-$ $30 \mathrm{Mn}-\mathrm{Ag}$ alloy resulted in the precipitation of Ag-rich particles on grain boundaries, which improved the yield strength significantly. The degradation rate of Ag-bearing alloy in Hank's solution was further accelerated because of the inducted microgalvanic corrosion. In addition, the Agbearing Fe-based alloy possessed a very low magnetic susceptibility and a good magnetic compatibility. Although the antibacterial properties need to be further investigated, the as-cast $\mathrm{Fe}-30 \mathrm{Mn}-\mathrm{Ag}$ alloy prepared by the rapid solidification was very promising biodegradable materials with good combination of mechanical properties as well as a proper degradation rate.

Acknowledgements This work was financially supported by the National Natural Science Foundation of China (No. 51671162), the Fundamental Research Funds for the Central Universities (Nos. XDJK2017B054 and XDJK2017D012), the Chongqing Research
Program of Basic Research and Frontier Technology (No. cstc2015jcyjBX0107) and the Venture and Innovation Support Program for Chongqing Overseas Returnees.

\section{References}

[1] S. Karimi, T. Nickchi, A.M. Alfantazi, Appl. Surf. Sci. 258, 6087 (2012)

[2] M. Niinomi, M. Nakai, J. Hieda, Acta Biomater. 8, 3888 (2012)

[3] Z. Xu, M.A. Hodgson, P. Cao, Mater. Sci. Eng. A 630, 116 (2015)

[4] Y.F. Zheng, X.N. Gu, F. Witte, Mater. Sci. Eng. R 77, 1 (2014)

[5] Y.J. Wang, J. Mater. Sci. Technol. 32, 801 (2016)

[6] C. Wang, H.T. Yang, Y.F. Zheng, J. Mater. Sci. Technol. 32, 909 (2016)

[7] F. Witte, Acta Biomater. 6, 1680 (2010)

[8] X.N. Gu, Y.F. Zheng, Front. Mater. Sci. China 4, 111 (2010)

[9] S.S. Chen, L. Li, B.C. Zhang, Y.H. Yang, J. Mater. Sci. Technol. 33, 469 (2016)

[10] W. Peng, L. Tan, K. Yang, J. Mater. Sci. Technol. 32, 827 (2016)

[11] J. Cheng, B. Liu, Y.H. Wu, Y.F. Zheng, J. Mater. Sci. Technol. 29, 619 (2013)

[12] T. Kraus, F. Moszner, S. Fischerauer, M. Fiedler, E. Martinelli, J. Eichler, F. Witte, E. Willbold, M. Schinhammer, M. Meischel, Acta Biomater. 10, 3346 (2014)

[13] M. Peuster, C. Hesse, T. Schloo, C. Fink, P. Beerbaum, S.C. Von, Biomaterials 27, 4955 (2006)

[14] H. Hendra, D. Dominique, M. Diego, J. Biomed. Mater. Res. A 93, 1 (2010)

[15] H. Hermawan, A. Purnama, D. Dube, J. Couet, D. Mantovani, Acta Biomater. 6, 1852 (2010)

[16] E. Mouzou, C. Paternoster, R. Tolouei, A. Purnama, P. Chevallier, D. Dubé, F. Prima, D. Mantovani, Mater. Sci. Eng. C 61, 564 (2016)

[17] B. Liu, Y.F. Zheng, L. Ruan, Mater. Lett. 65, 540 (2011)

[18] M. Schinhammer, A.C. Hänzi, J.F. Löffler, P.J. Uggowitzer, Acta Biomater. 6, 1705 (2010)

[19] D. Hong, D.T. Chou, O.I. Velikokhatnyi, A. Roy, B. Lee, I. Swink, I. Issaev, H.A. Kuhn, P.N. Kumta, Acta Biomater. 45, 375 (2016)

[20] S. Chernousova, M. Epple, Cheminform 44, 1636 (2013)

[21] L.G. Ning, S. Wang, X.F. Hu, C.M. Li, L.Q. Xu, J. Mater. Chem. B 5, 8814 (2017)

[22] J. Čapek, Š. Msallamová, E. Jablonská, J. Lipov, D. Vojtěch, Mater. Sci. Eng. C 79, 550 (2017)

[23] H.J. Zhang, D.F. Zhang, C.H. Ma, S.F. Guo, Mater. Lett. 92, 45 (2013)

[24] M. Moravej, F. Prima, M. Fiset, D. Mantovani, Acta Biomater. 6, 1726 (2010)

[25] Y.B. Wang, H.F. Li, Y.F. Zheng, M. Li, Mater. Sci. Eng. C 32, 599 (2012)

[26] H.C. Lin, K.M. Lin, C.S. Lin, T.M. Ouyang, Corros. Sci. 44, 2013 (2002)

[27] S.F. Guo, F.S. Pan, H.J. Zhang, D.F. Zhang, J.F. Wang, J. Miao, C. Su, C. Zhang, Mater. Des. 108, 624 (2016)

[28] ASTM G31-72 (2004), Standard Practice for Laboratory Immersion Corrosion Testing of Metals (ASTM International, West Conshohocken, 2004). www.astm.org. https://doi.org/10. 1520/g0031-72r04

[29] F. Witte, J. Fischer, J. Nellesen, H.A. Crostack, V. Kaese, A. Pisch, F. Beckmann, H. Windhagen, Biomaterials 27, 1013 (2006) 